\title{
Association between social and family support and antenatal depression: a hospital-based study in Chengdu, China
}

Ying $\mathrm{Hu}^{1,2,3 \dagger} \mathbb{D}$, Ying Wang ${ }^{4 \dagger}$, Shu Wen ${ }^{1,2,3,5 \dagger}$, Xiujing Guo ${ }^{1}$, Liangzhi $X u^{1,2,3}$, Baohong Chen ${ }^{5}$, Pengfan Chen ${ }^{5}$, Xiaoxia $\mathrm{Xu}^{5}$ and Yuqiong Wang ${ }^{4^{*}}$

\begin{abstract}
Background: Antenatal depression (AD) is considered as one of the major health burdens and has adverse effects on the outcome of expectant mothers and newborns. The present study aims to investigate the prevalence of antenatal depression (AD), and to explore the potential risk factors of AD among pregnant women in Chengdu, including personal background, related social factors, family factors and cognitive factors.

Methods: The prospective nested case-control study included pregnant women who were in their second pregnancy and attended prenatal care at three tertiary hospitals and one regional hospital in Chengdu, China, between March 2015 and May 2016. Self-designed questionnaires were given to participants in their second and third trimesters to collect information on clinical and demographic characteristics, and a modified edition of Edinburgh Postnatal Depression Scale (EPDS) were used to measure AD. The logistic regression was applicated in analyses.

Results: A total of 996 pregnant women were included in analysis. Ninety-three women suffered from AD symptoms only in their second trimester, 96 only in their third trimester, and 107 displayed persistent depression in both trimesters. In the univariate analyses, age and marital relationships were linked with AD occurrence in both second and third trimester. In addition, increasing age, full-time job, higher education level, and no gender preference of spouse were associated with reduced persistent depression. Multivariate analysis showed that gender preference and marital relationship were the potential risk factors of persistent depression.

Conclusions: Age, marital relationship relationships, with parents-in-law, the negative recognition of this pregnancy and husband's gender preference were found as risk factors of AD occurrence in some specific trimester. Gender preference of husbands and marital relationships were independently associated with persistent depression. These findings suggest that stronger family support can help improve mental health of pregnant women.
\end{abstract}

Keywords: Antenatal depression, Persistent depression, Risk factors, EPDS, China

\section{Background}

Antenatal depression (AD) is a major depressive disorder during pregnancy characterized by depressive symptoms including sadness or low mood, despondency, sleep disturbance, changes in appetite, suicidal ideation, feelings of worthlessness, loss of interest or pleasure,

\footnotetext{
* Correspondence: Yuqiong_w@126.com

'Ying Hu, Ying Wang and Shu Wen contributed equally to this work.

${ }^{4}$ Department of Nursing, Chengdu Women's and Children's Central Hospital,

School of Medicine, University of Electronic Science and Technology of

China, Chengdu, China

Full list of author information is available at the end of the article
}

etc., which may lead to devastating sequelae for the expectant mothers and families [1]. According to a systematic review, the pooled prevalence of prenatal depression estimates $9.2 \%$ in high-income countries and $19.2 \%$ in low-income and middle-income countries [2]. Based on publications that included patients at different trimesters and with varying demo-socio-economic status and used various study methodologies, the prevalence rate of $\mathrm{AD}$ among Chinese pregnant women ranges from 4 to $46.11 \%$ [3-5]. In addition, the reported prevalence of $\mathrm{AD}$ may be underestimated on account of the lower rate

(c) The Author(s). 2019 Open Access This article is distributed under the terms of the Creative Commons Attribution 4.0 International License (http://creativecommons.org/licenses/by/4.0/), which permits unrestricted use, distribution, and reproduction in any medium, provided you give appropriate credit to the original author(s) and the source, provide a link to the Creative Commons license, and indicate if changes were made. The Creative Commons Public Domain Dedication waiver (http://creativecommons.org/publicdomain/zero/1.0/) applies to the data made available in this article, unless otherwise stated. 
of identification and treatment in pregnant women compared with non-pregnant women [1]. There is growing evidence that $\mathrm{AD}$ not only affects pregnancy and neonatal outcomes, but also leads to the postnatal depression [6]. In addition, AD has influence on offspring's cognitive development, emotions and behaviors in childhood [7]. Much attention devoted to women with AD and efficacious treatment interventions are the keys of prenatal care. However, only about $50 \%$ AD patients are treated adequately at present [8]. What makes the treatment of AD more complicated is that many antidepressants cannot be simply applied due to potential side effects on the fetus [8].

$\mathrm{AD}$ may occur in any trimester during pregnancy. Persistent AD refers to depression that lasts for at least two trimesters among pregnant women. Multiple studies conducted in non-Asian populations showed that longterm or severe depression might change the hormone level in the body and reduce the uterine blood supply, thus increasing the risk of fatal distress, premature rupture of membranes and other complications [9]. However, few studies have explored the persistent $A D$ in China.

Several factors have been found to be associated with an increased risk of AD. Based on literature, potential risk factors mainly included four aspects: personal background, social and family aspect, obstetric aspect and cognitive aspect. Psychological and psychiatric factors such as previous history of mental illness, sociodemographic and economic factors such as ethnicity, employment, housing condition and income, social support, family relationships and life events had effect on $\mathrm{AD}$ occurrence to a certain extent $[10,11]$. In addition, other medical conditions regarding vomiting, anemia, and gestational diabetes might also be related to the development of $\mathrm{AD}$ [9]. Compared to western women, Chinese women seem more family-oriented and thus are more likely to be affected by family relationships. Meanwhile, Chinese society has strong desire to optimize the mental health of women and offspring [12]. Lau et al. [13] revealed financial support, marital status, family interpersonal relationships, and social support might contribute to AD patients living in the city of Chengdu, China, although they did not investigate the AD prevalence regarding a specific trimester.

We therefore performed a prospective nested casecontrol study to investigate the prevalence of $\mathrm{AD}$ among pregnant women in Chengdu, and to explore potential risk factors of $\mathrm{AD}$ occurrence and persistent depression in the pregnancy.

\section{Methods}

This study was conducted between March 2015 and May 2016 in three tertiary hospitals and one regional hospital in Chengdu, one of the central cities in Southwest China. Questionnaires were given to pregnant women who were scheduled for antenatal screening in one of the four hospitals, and each woman completed the questionnaires twice (in their second trimester and third trimester of the pregnancy, respectively). The questionnaires included two parts: I. General information (self-designed questions): (a) demographic factors; (b) social support factors; (c) obstetric factors; (d) cognitive aspects; II. Measurement of AD: the modified edition of 10-item Edinburgh Postnatal Depression Scale (EPDS) by Wang et al $[14,15]$, which is more suitable for Chinese population and is widely used for the maternal depression screening in mainland China. In the Mainland Chinese version of EPDS, a cutoff of 9.5 was recommended when screening for clinic depression, with a sensitivity of $80.00 \%$ and specificity of $83.03 \%$, respectively [15]. Participants were included if they: 1) were able to read and write Chinese and could complete the questionnaires; 2) agreed to participate in the survey; 3) had no existing psychological problems, such as depression, anxiety; 4) had no medical history of mental illness other than depression. This is based on information from the survey and related medical charts. A total of 1065 women meeting the above criteria were recruited. Among them, 55 women dropped out and the rest of 1010 women filled out two questionnaires. An additional 14 women were excluded from analysis due to "20\% blank" in the questionnaires or failure of completing questionnaire at both trimesters, leaving 996 women with valid questionnaires in the final analysis.

Categorical data were described using frequencies, and continuous data were described using means and standard deviations (SD). A multivariate logistic regression analysis was employed to identify independent risk factors of antenatal depression in terms of sociodemographic aspect, cognitive aspect and family aspect. Variables were entered for multivariate logistic regression analysis if the $P<0.05$ were considered statistically significant in the univariate analysis or if the variables were deemed clinically important regardless of the statistical significance. Estimated associations were described using odds ratios (OR) with 95\% confidence intervals (CIs). SPSS 25.0 (SPSS Chicago, IL, USA) was used for all statistical analyses. $P<0.05$ was considered statistically significant.

\section{Results}

A total of 996 eligible pregnant women who completed questionnaires both in their second and third trimesters were included for analyses. They were divided into four categories: non-depressive group (no depression in neither of the two trimesters) $(n=700)$, second trimesteronly depressive group $(n=93)$, third trimester-only depressive group $(n=96)$, and persistent depressive 
group (i.e., depressive at both time points, $n=107$ ). The flow chart is demonstrated in Fig. 1.

Table 1 contains the socio-demographic characteristics, cognitive condition about this pregnancy, family background and obstetric characteristics of study participants. The mean age of the respondents were 28.93 years $(\mathrm{SD}=3.76)$. Results showed that most participants had lived in Chengdu for more than 5 years $(n=726$, $72.89 \%)$, and the majority pregnant women had full-time job $(n=769,77.21 \%)$ and higher education $(n=749$, $75.20 \%)$. The housing area of few respondents (9.94\%) spanned over $140 \mathrm{~m}^{2}$ and participants who owned housing property rights accounted for $86.45 \%$.

As for the cognitive aspect, majority of the pregnant women had a general understanding of pregnancy knowledge $(n=944,94.78 \%)$ and had planned for this pregnancy $(n=738,74.25 \%)$. In addition, $87.45 \%$ of them were happy with the pregnancy and $93.77 \%$ concerned for the fetal health.

Displayed in the family aspect was, around $20 \%$ of participants $(n=200)$ reported that their spouses had gender preference. There were $88.65 \%$ participants having good relationship with their husbands in the last 3 months, 843 (84.64\%) participants had close relationship with their parents-in-law and $94.38 \%$ had good relationship with their own parents. Considering the obstetric characteristics, the mean number of times of gravidity, parity, spontaneous abortion, induced abortion was 2.11, $0.08,0.16$ and 0.91 , respectively. $59.44 \%$ pregnancy women had history of gynecological and obstetric diseases such as dysmenorrhea and dystocia.
Table 2 contains the results of univariate of social support. Compared with non-depressive group, older age was a protective factor for the occurrence of antenatal depression (second trimester depressive group vs. nondepressive group: $(\mathrm{OR}=0.938,95 \% \mathrm{CI}$ : $0.883-0.996, P<$ $0.05)$; third trimester depressive group vs. nondepressive group: $(\mathrm{OR}=0.925,95 \% \mathrm{CI}$ : $0.871-0.982, P<$ $0.05)$; persistent depressive group vs. non-depressive group: $(\mathrm{OR}=0.944,95 \% \mathrm{CI}$ : $0.892-0.998, P<0.05)$ ). Similarly, participants with full-time job $(\mathrm{OR}=0.603,95 \% \mathrm{CI}$ : $0.379-0.959, P<0.05)$ and higher education $(\mathrm{OR}=0.608$, 95\%CI: $0.393-0.940, P<0.05)$ in the persistent depressive group also showed lower likelihood of depression.

Regarding family support and cognitive aspect, $\mathrm{AD}$ was significantly lower in pregnant women whose husbands had no gender preference $(\mathrm{OR}=0.459,95 \% \mathrm{CI}$ : $0.261-0.807, P<0.05)$. Poor marital relationship was a risk factor for second trimester depression $(\mathrm{OR}=3.419$, 95\%CI: .980-5.904, $P<0.05)$ and third trimester depression $(\mathrm{OR}=4.624,95 \% \mathrm{CI}: 2.830-7.555, P<0.05)$. Poor relationships with parents-in-law or own parents were significant predictors of the third trimester depression $(\mathrm{OR}=1.635,95 \% \mathrm{CI}: 1.010-2.646, P<0.05)$ in third trimester depressive group. Pregnant women who considered the pregnancy as a task also had elevated risk of depression in the third trimester $(\mathrm{OR}=2.879,95 \% \mathrm{CI}$ : 1.528-5.426, $P<0.05$ ). (Table 3).

As showed in Table 4, seven factors entered the multivariate logistic regression analysis. According to the result, maternal age was independent risk factor both in second trimester depressive group and third depressive

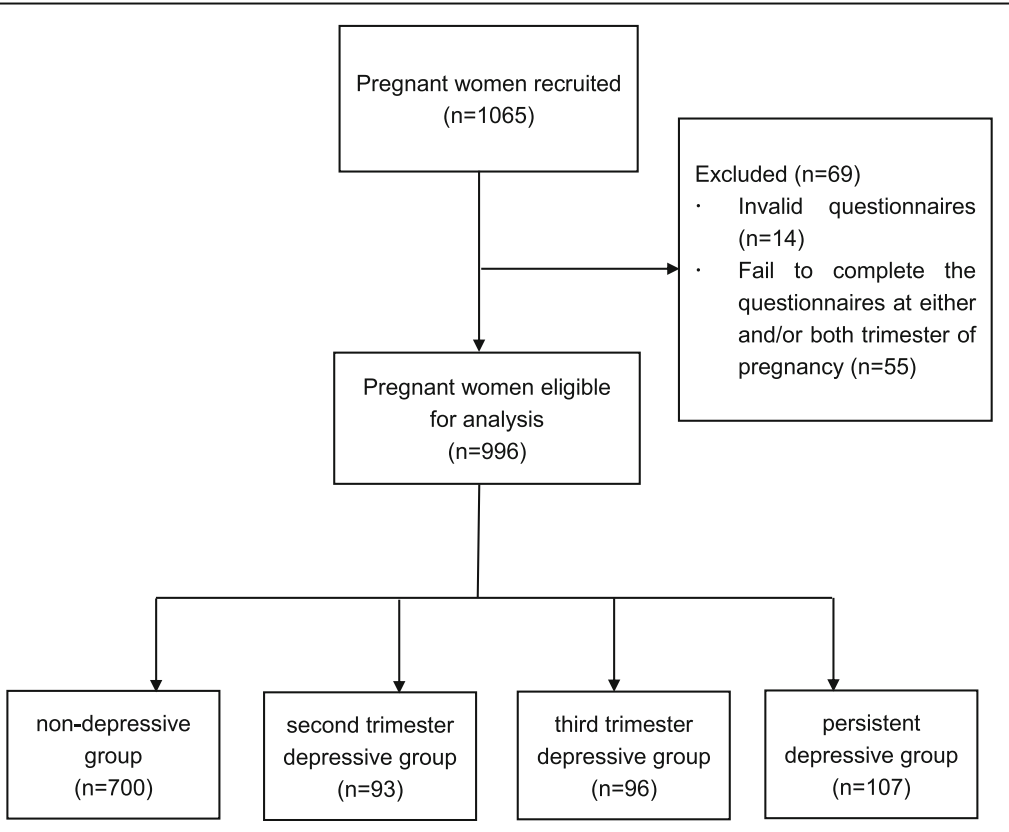

Fig. 1 Flow diagram of the study 
Table 1 Baseline characteristics of included pregnant women

\begin{tabular}{|c|c|c|c|c|c|}
\hline & $\begin{array}{l}\text { Non-depressive group } \\
(N=700,70.28 \%)\end{array}$ & $\begin{array}{l}\text { Second trimester } \\
\text { depressive group } \\
(N=93,9.34 \%)\end{array}$ & $\begin{array}{l}\text { Third trimester } \\
\text { depressive group } \\
(\mathrm{N}=96,9.64 \%)\end{array}$ & $\begin{array}{l}\text { persistent } \\
\text { depressive group } \\
(N=107,10.72 \%) \\
\end{array}$ & $\begin{array}{l}\text { Overall } \\
\text { number } \\
(N=996)\end{array}$ \\
\hline \multicolumn{6}{|c|}{ Demographic data and social satus } \\
\hline Maternal age (Mean $\pm S D)$ & $29.20 \pm 3.80$ & $28.32 \pm 3.59$ & $28.15 \pm 3.67$ & $28.40 \pm 3.50$ & $28.93 \pm 3.76$ \\
\hline \multicolumn{6}{|l|}{ Educational level } \\
\hline Primary school & $5(0.71)$ & $0(0.00)$ & $2(2.08)$ & $2(1.87)$ & $9(0.90)$ \\
\hline Secondary school & $124(17.71)$ & $16(17.20)$ & $18(18.75)$ & $26(24.30)$ & $184(18.47)$ \\
\hline Bachelor and above & $540(77.14)$ & $69(74.19)$ & $70(72.92)$ & $70(65.42)$ & 749 (75.20) \\
\hline Unknown & $31(4.43)$ & $8(8.60)$ & $6(6.25)$ & $9(8.41)$ & $54(5.42)$ \\
\hline \multicolumn{6}{|l|}{ Employment $^{\mathrm{a}}$} \\
\hline Part-time job & $24(3.43)$ & $4(4.30)$ & $4(4.17)$ & $1(0.93)$ & $33(3.31)$ \\
\hline Full time job & $546(78.00)$ & $72(77.42)$ & $75(78.13)$ & $76(71.03)$ & $769(77.21)$ \\
\hline Unemployed & $130(18.57)$ & $17(18.28)$ & $17(17.71)$ & $30(28.04)$ & $194(19.48)$ \\
\hline \multicolumn{6}{|l|}{ Years of living in Chengdu } \\
\hline$<5$ years & $183(26.14)$ & $28(30.11)$ & $27(28.13)$ & $32(29.91)$ & $270(27.11)$ \\
\hline $6-10$ years & $196(28.00)$ & $27(29.03)$ & $33(34.38)$ & $33(30.84)$ & $289(29.02)$ \\
\hline $11-20$ years & $105(15.00)$ & $13(13.98)$ & $6(6.25)$ & $14(13.08)$ & $138(13.86)$ \\
\hline$>20$ years & $216(30.86)$ & $25(26.88)$ & $30(31.25)$ & $28(26.17)$ & $299(30.02)$ \\
\hline \multicolumn{6}{|c|}{ Family income per capita (Yuan) } \\
\hline$<1200$ & $21(3.00)$ & $3(3.23)$ & $2(2.08)$ & $3(2.80)$ & $29(2.91)$ \\
\hline $1200-2000$ & $69(9.86)$ & $6(6.45)$ & $12(12.50)$ & $13(12.15)$ & $100(10.04)$ \\
\hline $2001-3000$ & $101(14.43)$ & $15(16.13)$ & $20(20.83)$ & $20(18.69)$ & $156(15.66)$ \\
\hline $3001-4000$ & $141(20.14)$ & $19(20.43)$ & $15(15.63)$ & $19(17.76)$ & $194(19.48)$ \\
\hline$>4000$ & $368(52.57)$ & $50(53.76)$ & $47(48.96)$ & $52(48.60)$ & $517(51.91)$ \\
\hline \multicolumn{6}{|l|}{ Types of residence } \\
\hline Have property rights & $606(86.57)$ & $79(84.95)$ & $84(87.50)$ & $92(85.98)$ & $861(86.45)$ \\
\hline No property rights & $94(13.43)$ & $14(15.05)$ & $12(12.50)$ & $15(14.02)$ & $135(13.55)$ \\
\hline \multicolumn{6}{|l|}{ Size of residence } \\
\hline$<90 \mathrm{~m}^{2}$ & $315(45.00)$ & $46(49.46)$ & $46(47.92)$ & $53(49.53)$ & $460(46.18)$ \\
\hline $90-140 \mathrm{~m}^{2}$ & $309(44.14)$ & $40(43.01)$ & $43(44.79)$ & $45(42.06)$ & 392 (39.36) \\
\hline$>140 \mathrm{~m}^{2}$ & 76 (10.86) & $7(7.53)$ & 7 (7.29) & $9(8.41)$ & 99 (9.94) \\
\hline \multicolumn{6}{|l|}{ Cognitive factors } \\
\hline \multicolumn{6}{|c|}{ Degree of pregnancy knowledge } \\
\hline Incomprehension & $4(0.57)$ & $0(0.00)$ & $0(0.00)$ & $1(0.93)$ & $5(0.50)$ \\
\hline General understanding & $662(94.57)$ & $90(96.77)$ & $91(94.79)$ & $101(94.39)$ & 944 (94.78) \\
\hline Deep understanding & $34(4.86)$ & $3(3.23)$ & $5(5.21)$ & $5(4.67)$ & $47(4.72)$ \\
\hline \multicolumn{6}{|l|}{ Attending maternity school } \\
\hline Yes & $388(55.43)$ & $47(50.54)$ & $57(59.38)$ & $70(65.42)$ & $562(56.43)$ \\
\hline No & $312(44.57)$ & $46(49.46)$ & $39(40.63)$ & $37(34.58)$ & $434(43.57)$ \\
\hline \multicolumn{6}{|l|}{ Planned pregnancy } \\
\hline Intended pregnancy & $529(75.58)$ & $63(67.74)$ & $73(76.04)$ & $73(68.22)$ & $738(74.25)$ \\
\hline Unintended pregnancy & $158(22.64)$ & $26(27.96)$ & $22(22.92)$ & $32(29.91)$ & $238(23.94)$ \\
\hline Unknown & $13(1.58)$ & $4(4.30)$ & $1(1.04)$ & $2(1.87)$ & $20(2.01)$ \\
\hline \multicolumn{6}{|c|}{ The recognition of this pregnancy } \\
\hline Task & $44(6.29)$ & $6(6.45)$ & $15(15.63)$ & $10(9.35)$ & $75(7.53)$ \\
\hline
\end{tabular}


Table 1 Baseline characteristics of included pregnant women (Continued)

\begin{tabular}{|c|c|c|c|c|c|}
\hline & $\begin{array}{l}\text { Non-depressive group } \\
(N=700,70.28 \%)\end{array}$ & $\begin{array}{l}\text { Second trimester } \\
\text { depressive group } \\
(N=93,9.34 \%)\end{array}$ & $\begin{array}{l}\text { Third trimester } \\
\text { depressive group } \\
(N=96,9.64 \%)\end{array}$ & $\begin{array}{l}\text { persistent } \\
\text { depressive group } \\
(N=107,10.72 \%)\end{array}$ & $\begin{array}{l}\text { Overall } \\
\text { number } \\
(N=996)\end{array}$ \\
\hline Burden & $26(3.71)$ & $4(4.30)$ & $7(7.29)$ & $5(4.67)$ & $42(4.22)$ \\
\hline Pleasure & $625(89.29)$ & $83(89.25)$ & $74(77.08)$ & $89(83.18)$ & $871(87.45)$ \\
\hline Other & $5(0.71)$ & $0(0.00)$ & 0 & $3(2.80)$ & $8(0.80)$ \\
\hline \multicolumn{6}{|l|}{ Concern for fetal health } \\
\hline Yes & $651(93.13)$ & $87(93.55)$ & $92(95.83)$ & $103(96.26)$ & $933(93.77)$ \\
\hline No & $48(6.87)$ & $6(6.45)$ & $4(4.17)$ & $4(3.74)$ & $62(6.23)$ \\
\hline \multicolumn{6}{|l|}{ Family support } \\
\hline \multicolumn{6}{|c|}{ Gender expectations for the fetus of the spouse } \\
\hline No & $575(82.14)$ & $75(80.65)$ & $70(72.92)$ & $76(71.03)$ & $796(79.92)$ \\
\hline Boys & $59(8.43)$ & $9(9.68)$ & $14(14.58)$ & $12(11.21)$ & $94(9.44)$ \\
\hline Girls & $66(9.43)$ & $9(9.68)$ & $12(12.50)$ & $19(17.76)$ & $106(10.64)$ \\
\hline \multicolumn{6}{|l|}{ Marital relationship in the last 3 months ${ }^{\mathrm{a}}$} \\
\hline Good & $649(92.71)$ & $72(77.42)$ & $84(87.50)$ & $78(72.90)$ & $883(88.65)$ \\
\hline General & $50(7.14)$ & $21(22.58)$ & $12(12.50)$ & $27(25.23)$ & $110(11.04)$ \\
\hline Poor & $2(1.87)$ & $0(0.00)$ & $0(0.00)$ & $1(0.14)$ & $3(0.30)$ \\
\hline \multicolumn{6}{|c|}{ Relationship with parents-in-law in the last 3 months } \\
\hline Good & $594(84.86)$ & $80(86.02)$ & $75(78.13)$ & $94(87.85)$ & $843(84.64)$ \\
\hline General & $104(14.86)$ & $12(12.90)$ & 19 (19.79) & $12(11.21)$ & $147(14.76)$ \\
\hline Poor & $2(0.29)$ & $1(1.08)$ & $2(2.08)$ & $1(0.93)$ & $6(0.60)$ \\
\hline \multicolumn{6}{|c|}{ Relationship with own parents in the last 3 months } \\
\hline Good & $658(94.00)$ & $92(98.92)$ & $87(90.63)$ & $103(96.26)$ & $940(94.38)$ \\
\hline General & $42(6.00)$ & $1(1.08)$ & $9(9.38)$ & $4(3.74)$ & $56(5.62)$ \\
\hline \multicolumn{6}{|l|}{ Obstetric factors } \\
\hline Gravidity (Mean \pm SD) & $2.09 \pm 1.27$ & $2.29 \pm 1.54$ & $1.96 \pm 129$ & $2.23 \pm 1.43$ & $2.11 \pm 1.31$ \\
\hline Parity (Mean \pm SD) & $0.08 \pm 0.30$ & $0.03 \pm 0.18$ & $0.09 \pm 0.33$ & $0.09 \pm 0.29$ & $0.08 \pm 0.29$ \\
\hline Spontaneous abortion (Mean \pm SD) & $0.13 \pm 0.43$ & $0.26 \pm 0.66$ & $0.16 \pm 0.49$ & $0.27 \pm 0.70$ & $0.16 \pm 0.50$ \\
\hline Induced abortion (Mean \pm SD) & $0.90 \pm 1.12$ & $0.99 \pm 1.33$ & $0.80 \pm 0.97$ & $0.99 \pm 1.20$ & $0.91 \pm 1.14$ \\
\hline \multicolumn{6}{|l|}{ Morning sickness } \\
\hline Yes & $597(85.29)$ & $81(87.10)$ & $87(90.625)$ & $99(92.52)$ & $864(86.75)$ \\
\hline No & $103(14.71)$ & $12(12.90)$ & $9(9.375)$ & $8(7.48)$ & $132(13.25)$ \\
\hline \multicolumn{6}{|c|}{ Previous history about obstetrical and gynecological disease } \\
\hline Yes & $406(0.58)$ & 5356.99) & $61(63.54)$ & $72(67.29)$ & $592(59.44)$ \\
\hline No & $294(0.42)$ & $40(43.01)$ & $35(36.46)$ & $35(32.71)$ & $404(40.56)$ \\
\hline \multicolumn{6}{|l|}{ Assisted reproduction } \\
\hline Yes & $12(1.71)$ & $2(2.15)$ & $0(0.00)$ & $3(2.80)$ & $17((1.71)$ \\
\hline No & $688(98.29)$ & $91(97.85)$ & $96(100.00)$ & $104(97.20)$ & $979(98.29)$ \\
\hline
\end{tabular}

$N$ number of included pregnant women $m^{2}$ square meters; $S D$ standard deviation

${ }^{\mathrm{a}}$ Missing data

group. Poor relationship with parents-in-law and pregnant women who considered pregnancy as task were associated with higher third trimester depression. Additionally, poor marital relationship with the last 3 months was a predictor factor for pregnant women in second trimester depressive group $(\mathrm{OR}=$
3.188, 95\%CI: 1.759-5.780, $P<0.05)$ and persistent depressive group $(\mathrm{OR}=4.772,95 \% \mathrm{CI}: 2.792-8.155$, $P<0.05)$. Furthermore, no spouse gender expectation for the fetus was a protective factor of persistent depression of pregnant women $(\mathrm{OR}=0.400,95 \% \mathrm{CI}$ : 0.221-0.726, $P<0.05$ ). 
Table 2 Univariate analysis of the association between sociodemographic characteristics and antenatal depression

\begin{tabular}{|c|c|c|c|}
\hline & $\begin{array}{l}\text { Second trimester } \\
\text { depressive group } \\
(N=93)\end{array}$ & $\begin{array}{l}\text { Third trimester } \\
\text { depressive group } \\
(N=96)\end{array}$ & $\begin{array}{l}\text { persistent depressive } \\
\text { group }(N=107)\end{array}$ \\
\hline & OR $(95 \% \mathrm{Cl})$ & OR $(95 \% \mathrm{Cl})$ & OR $(95 \% \mathrm{Cl})$ \\
\hline Age & $0.938(0.883,0.996)^{b}$ & $0.925(0.871,0.982)^{b}$ & $0.944(0.892,0.998)^{b}$ \\
\hline Educational level & $1.073(0.619,1.860)$ & $0.795(0.489,1.294)$ & $0.608(0.393,0.940)^{b}$ \\
\hline Family income per capita & $1.045(0.861,1.268)$ & $0.913(0.764,1.091)$ & $0.915(0.772,1.085)$ \\
\hline Size of residence & $0.832(0.593,1.166)$ & $0.859(0.617,1.195)$ & $0.848(0.618,1.164)$ \\
\hline \multicolumn{4}{|l|}{ Years of living in Chengdu } \\
\hline$\leq 5$ years & $1.322(0.745,2.347)$ & $1.062(0.609,1.852)$ & $1.349(0.783,2.324)$ \\
\hline $6-10$ years & $1.190(0.668,2.120)$ & $1.212(0.713,2.061)$ & $1.299(0.757,2.228)$ \\
\hline $11-20$ years & $1.070(0.526,2.175)$ & $0.411(0.166,1.019)$ & $1.029(0.520,2.036)$ \\
\hline \multicolumn{4}{|l|}{$>20$ years $^{a}$} \\
\hline \multicolumn{4}{|l|}{ Employment } \\
\hline Part-time & $1.275(0.394,4.119)$ & $1.275(0.394,4.119)$ & $0.181(0.023,1.388)$ \\
\hline Full time & $1.008(0.575,1.769)$ & $1.050(0.600,1.839)$ & $0.603(0.379,0.959)^{b}$ \\
\hline \multicolumn{4}{|l|}{ Unemployed $^{\text {a }}$} \\
\hline \multicolumn{4}{|l|}{ Types of residence } \\
\hline Have property rights & $0.875(0.476,1.608)$ & $1.086(0.571,2.065)$ & $0.951(0.529,1.712)$ \\
\hline No property rights ${ }^{a}$ & & & \\
\hline
\end{tabular}

\section{Discussion}

To our knowledge, this is the first study investigating persistent $\mathrm{AD}$ across the second and third trimesters of pregnant women without interventions in Southwest China. Results of univariate analyses showed that older age, full-time job and higher educational levels were negatively associated with risk of persistent $A D$ in their second and third trimesters. Regarding the family support, spouses of the participants with no gender preference may favorably affect the outcome of persistent depression. Moreover, the relationships with husbands and with parents-in-law had disproportionate influence on the antenatal depression of the pregnant women in their second or third trimester. In the multivariate analysis, pregnant women whose husbands had no expectations of fetal sex or got on well with them were less likely to get overwhelmed by persistent AD. However, women exposed to detrimental relationships with their parents-in-law had a significant elevated risk of $\mathrm{AD}$ in the third trimester. The results showed that the mutual influence of social support and family support might play a crucial role in antenatal depression of pregnant women in different trimesters in Chengdu.

Recently, there is evidence suggesting that $\mathrm{AD}$ is becoming increasingly prevalent. Therefore, studies on specific groups who were at high risk of developing depression may assist in early identification, intervention and prevention [11, 16]. Gavin et al. [17] reported a decrease in the $\mathrm{AD}$ prevalence rates as delivery period drawing near, whereas Bennett et al [18] found rates in the second and third trimesters almost as twice as the first trimester. Despite the limited local evidence and large disparity of these studies, the results indicated that high rate of $\mathrm{AD}$ tended to occur in women who lived in the context of social and family adversity. Compared with Western women, Chinese women tended to implicitly manifest their depression through somatic complaints thus the reported incidence were possibly underestimated in the present study [19]. Besides, crude findings in Bayrampour et al [20] similarly found $11.1 \%$ pregnant women admitted in the study, and the study showed that the prevalence of persistent depression lasted in the second-third trimester group was $2.5 \%$, which was lower than transient depression (symptomatic exclusively in the second trimester) [20]. However, the duration of depressive status may be linked with the severity of adverse maternal and child outcomes, which may be attributed to the alterations in hyperactive hypothalamo-pituitary-adrenal cortical axis and the inflammatory system [21]. Our results extended the risk factors in transient $\mathrm{AD}$ to the common $\mathrm{AD}$ risk factors persisting in second and third trimesters, aiding in the integration of trajectories of perinatal depression and the development of the underlying mechanisms and causal 
Table 3 Univariate analysis of risk factors associated with antenatal depression in family support and cognition aspects among pregnant women

\begin{tabular}{|c|c|c|c|}
\hline & $\begin{array}{l}\text { Second trimester } \\
\text { depressive group } \\
(N=93)\end{array}$ & $\begin{array}{l}\text { Third trimester } \\
\text { depressive group } \\
(N=96)\end{array}$ & $\begin{array}{l}\text { persistent depressive } \\
\text { group }(N=107)\end{array}$ \\
\hline & OR $(95 \% \mathrm{Cl})$ & OR $(95 \% \mathrm{Cl})$ & OR $(95 \% \mathrm{Cl})$ \\
\hline Degree of knowledge of pregnancy & $0.798(0.286,2.232)$ & $1.186(0.484,2.906)$ & $0.894(0.351,2.274)$ \\
\hline Relationship with husband in the last 3 months & $3.419(1.980,5.904)^{b}$ & $4.624(2.830,7.555)^{b}$ & $1.748(0.908,3.366)$ \\
\hline Relationship with parents-in-law in the last 3 months & $0.974(0.545,1.741)$ & $1.635(1.010,2.646)^{b}$ & $0.836(0.469,1.491)$ \\
\hline Relationship with own parents in the last 3 months & $0.170(0.023,1.252)$ & $1.621(0.763,3.444)$ & $0.608(0.214,1.732)$ \\
\hline \multicolumn{4}{|l|}{ Attending maternity knowledge lecture } \\
\hline Yes & $1.217(0.789,1.877)$ & $0.851(0.551,1.313)$ & $0.657(0.430,1.006)$ \\
\hline \multicolumn{4}{|l|}{$\mathrm{No}^{\mathrm{a}}$} \\
\hline \multicolumn{4}{|l|}{ Planned pregnancy } \\
\hline Intended pregnancy & $0.724(0.443,1.182)$ & $0.991(0.596,1.648)$ & $0.681(0.434,1.071)$ \\
\hline \multicolumn{4}{|l|}{ Unintended pregnancy ${ }^{a}$} \\
\hline \multicolumn{4}{|l|}{ The recognition of this pregnancy } \\
\hline Task & $1.027(0.425,2.483)$ & $2.879(1.528,5.426)^{b}$ & $1.596(0.776,3.284)$ \\
\hline Burden & $1.158(0.394,3.402)$ & $2.274(0.954,5.420)$ & $1.350(0.506,3.607)$ \\
\hline \multicolumn{4}{|l|}{ Pleasure $^{a}$} \\
\hline \multicolumn{4}{|l|}{ Concern for fetal health } \\
\hline Yes & $1.069(0.444,2.572)$ & $1.696(0.598,4.813)$ & $1.899(0.670,5.377)$ \\
\hline \multicolumn{4}{|l|}{$\mathrm{No}^{\mathrm{a}}$} \\
\hline \multicolumn{4}{|l|}{ Spouse gender expectations for the fetus } \\
\hline No & $0.957(0.458,1.998)$ & $0.670(0.345,1.300)$ & $0.459(0.261,0.807)^{b}$ \\
\hline Girls & $1.119(0.416,3.006)$ & $1.305(0.559,3.045)$ & $0.707(0.316,1.578)$ \\
\hline Boys $^{a}$ & & & \\
\hline
\end{tabular}

pathways in which poor depressive status leads to adverse outcomes.

The results of both univariate and multivariate analysis revealed that maternal age was an important sociodemographic risk factor in $\mathrm{AD}$, which had been demonstrated in several studies $[10,13]$. Previous studies showed that younger women had an increased risk of AD due to the vulnerability and dependency when they were young [13, 22, 23]. However, one study [5] conducted in Shanghai has opposite finding, showing that older women were more likely to have AD because more pregnant complications and stressful life events were associated with the higher $\mathrm{AD}$ rates in older pregnant women. The divergence might be related to the different age ranges of pregnant women included in the studies [24]. For example, pregnant women with older maternal age might have more complications, which might be regarded as "confounding by indication" [24]. This was also the potential explanation that older maternal age was not considered as an independent predictor for second and third persistent depressive group in multivariate model. Consistent with previous studies, employment and higher educational level of pregnant women were related to the $\mathrm{AD}$ prevalence [25]. It has been found that women in the setting of full-time work and higher educational level had good social support, and they were less likely to have economic concern and to have pessimistic view on pregnancy complications. Instead, they were more likely to seek medical help for any pain or stress relief $[18,26]$. However, the two factors were not statistically significant in multivariate analysis. One possible reason was that senior intellectual females might encounter with more difficulties and challenges with the expansion of high education and increased female employment in China, and they were also more likely to experience the rapid shift in family values. Therefore, they may postpone childbearing to high-risk age for pregnancy [27]. Another possible explanation was that individuals with good education were more sensitive to and not embarrassed about admitting depression [28]. Our 
Table 4 Multivariate logistic regression analysis of potential risk factors of antenatal depression

\begin{tabular}{|c|c|c|c|}
\hline & $\begin{array}{l}\text { Second trimester } \\
\text { depressive group } \\
(N=93)\end{array}$ & $\begin{array}{l}\text { Third trimester } \\
\text { depressive group } \\
(N=96)\end{array}$ & $\begin{array}{l}\text { persistent depressive } \\
\text { group }(N=107)\end{array}$ \\
\hline & OR $(95 \% \mathrm{Cl})$ & OR $(95 \% \mathrm{Cl})$ & OR $(95 \% \mathrm{Cl})$ \\
\hline Age & $0.928(0.868,0.991)^{b}$ & $0.918(0.861,0.980)^{b}$ & $0.951(0.895,1.011)$ \\
\hline Educational level & $1.293(0.713,2.344)$ & $0.947(0.562,1.597)$ & $0.775(0.470,1.277)$ \\
\hline Relationship with husband in the last 3 months & $3.188(1.759,5.780)^{b}$ & $1.571(0.793,3.115)$ & $4.772(2.792,8.155)^{b}$ \\
\hline Relationship with parents-in-law in the last 3 months & $0.870(0.452,1.674)$ & $1.796(1.070,3.017)^{b}$ & $0.765(0.397,1.475)$ \\
\hline \multicolumn{4}{|l|}{ Employment } \\
\hline Part-time job & $1.075(0.283,4.075)$ & $1.401(0.415,4.722)$ & - \\
\hline Full time job & $1.026(0.554,1.899)$ & $0.932(0.510,1.703)$ & $0.918(0.524,1.611)$ \\
\hline \multicolumn{4}{|l|}{ Unemployed $^{\mathrm{a}}$} \\
\hline \multicolumn{4}{|l|}{ The recognition of this pregnancy } \\
\hline Task & $0.947(0.373,2.404)$ & $2.850(1.424,5.702)^{b}$ & $0.865(0.360,2.080)$ \\
\hline Burden & $1.323(0.430,4.069)$ & $2.316(0.925,5.802)$ & $0.993(0.321,3.074)$ \\
\hline \multicolumn{4}{|l|}{ Pleasure $^{a}$} \\
\hline \multicolumn{4}{|l|}{ Gender expectations for the fetus of the spouse } \\
\hline No & $1.034(0.471,2.267)$ & $0.627(0.318,1.239)$ & $0.400(0.221,0.726)^{b}$ \\
\hline Girls & $1.028(0.341,3.094)$ & $1.164(0.478,2.831)$ & $0.702(0.294,1.673)$ \\
\hline Boys $^{a}$ & & & \\
\hline
\end{tabular}

finding did not show any association between years of living in Chengdu and AD incidence, which was not consistent with the findings from Lau et al. [13]. Lau et al. highlighted the importance of migrant-related factors occurring in the rapidly developing country [13]. However, with the rapid development of Chengdu, the living environment and public welfare for new migrants and members of their families, such as subsidized housing, education, and medical benefits, have been dramatically improved so that women with shorter time in Chengdu could be free from these issues.

Of the family-related factors, relationships with family members, especially with husband, had valuable prognostic significance for AD. Although it has been well known that active support from partner was a pivotal instrument in the mental health of pregnant women, support from extended family was also of importance for the consanguinity relationship and the idea of conformity in Chinese culture [12]. Likewise, the traditional preference for boys to girls are still deeply rooted in Chinese people, especially in rural areas. Adewuya et al. [29] found the delivery of a female baby was a predictor of postnatal depression, which was consistent to our finding to some extent. As the result showed, spouse gender expectations for the baby and the relationship with husband were statistically associated with second-third trimester $A D$, suggesting that practical support, such as no gender preference for fetus, might reduce the undesirable psychological burden of pregnant women [11].

Apart from the well-known risk factors, a longitudinal pregnancy cohort with the similar setting, summarized three elements as the risk factors of chronic depressive and anxiety symptoms, including high perceived stress, low social support, and the history of mental health problems, which were consistent with our results to some extent [20]. Mora et al. showed multiparous women were more likely to be chronically depressive compared with other women [30] and Chung et al. noted that persistent depressive symptoms through the perinatal period was related to poor parenting practices [31]. Additionally, biological variables did act on AD indirectly through their significant effects on psychosocial stressors and symptoms of perinatal mood disorders [32].

There were some limitations of this study. Firstly, the study was hospital-based, and the representative of the sample was limited if pregnant women with AD were unwilling or unable to attend the screening. Meanwhile, patients with some physical or mental illness which were also considered as risk factors of AD are more likely to be excluded from the study. Secondly, data collected from the self-report psychometric questionnaires may be subject to recall bias. Thirdly, we did not evaluate the obstetrical risk factors in the present study, and we were 
unable to determine whether it is causal association between $\mathrm{AD}$ and risk factors mentioned above. Besides, too many obstetrical factors need to be taken into account and some factors such as pregnancy complications are changeable along with the pregnant period. Moreover, these limitations will hopefully be addressed in future research.

\section{Conclusions}

In conclusion, the current mental health of pregnant women during pregnant is not optimistic in Chengdu. Of these $\mathrm{AD}$ women, more than a third of pregnant women represent persistent depressive symptoms. In addition, there are some factors related to $\mathrm{AD}$ in specific trimester or in persistent depression among pregnant women in Chengdu, including maternal age, the recognition of the pregnancy, spouse sex expectations for the fetus, and relationships with family members. The study may help professionals identify high-risk pregnant women and help them collaborate with family members to improve the mental health of these women. Further research on exposure factors and the effective interventions of $\mathrm{AD}$ is warranted.

\section{Abbreviations}

AD: Antenatal depression; EPDS: Edinburgh Postnatal Depression Scale; $\mathrm{m}^{2}$ : Square meters; OR: Odds ratios; RMB: Renminbi; SD: Standard deviations

\section{Acknowledgements}

The authors would like to thank the expert assistance of Ms. Peiran Chen from National Office of Maternal and Child Health Surveillance of China.

\section{Authors' contributions}

Y.H, Y. W and S. W contributed to the planning of the paper and study design, Y. H and S. W contributed to the data analysis and writing the manuscript. X.J.G contributed to the data collection and analysis. Y. W, B.H.C, P.F.C and X.X.X contributed to data collection and revising the manuscript. L.Z.X and Y.Q.W contributed to data handling and revising the manuscript. All authors read and approved the final manuscript.

\section{Funding}

This study was supported by the National Natural Science Foundation for Youth (China, NO. 21507094) and Clinical Research Fund of Sichuan University West China Second University Hospital in 2016 (NO. KL008). As the main investigator of the two funding bodies (the National Natural Science Foundation for Youth (China, NO. 21507094) and Clinical Research Fund of Sichuan University West China Second University Hospital in 2016 (NO. KL008)), Dr. Ying Hu is also the principal researcher of the project and provided a small part of the two funding to support the data analysis of the study.

\section{Availability of data and materials}

The datasets used and analyzed during the current study are available from the corresponding author on reasonable request.

\section{Ethics approval and consent to participate}

The study was approved by the Institution Review Board of Chengdu Women and Children's Central Hospital Ethical approval. All procedures performed in studies involving human participants were in accordance with the ethical standards of the institutional and/or national research committee (Chengdu Women and Children's Central Hospital Ethical) and with the 1964 Helsinki declaration and its later amendments or comparable ethical standards. Written informed consent was obtained before data collection. Personal identifiers were removed before data analysis. Study objectives were clearly explained to all participants; participants were informed of the right to withdraw their participation any time during the interview.

Consent for publication

Not applicable.

\section{Competing interests}

The authors declare that they have no conflicts of interest.

\section{Author details}

'Department of Obstetrics and Gynecology, West China Second University Hospital, Chengdu, China. ${ }^{2}$ Key Laboratory of Birth Defects and Related

Diseases of Women and Children (Sichuan University), Ministry of Education, Sichuan University, Chengdu, China. ${ }^{3}$ Reproductive Endocrinology and Regulation Laboratory, West China Second University Hospital, Sichuan University, Chengdu 610041, China. ${ }^{4}$ Department of Nursing, Chengdu Women's and Children's Central Hospital, School of Medicine, University of Electronic Science and Technology of China, Chengdu, China. ${ }^{5}$ West China School of Medicine, Sichuan University, Chengdu, China.

Received: 14 December 2018 Accepted: 13 September 2019

Published online: 19 November 2019

\section{References}

1. Howard LM, Molyneaux E, Dennis CL, Rochat T, Stein A, Milgrom J. Nonpsychotic mental disorders in the perinatal period. Lancet. 2014;384(9956): 1775-88.

2. Woody CA, Ferrari AJ, Siskind DJ, Whiteford HA, Harris MG. A systematic review and meta-regression of the prevalence and incidence of perinatal depression. J Affect Disord. 2017;219:86-92.

3. Shi SX, Tang YF, Cheng LN, Su QF, Qi K, Yang YZ. An investigation of the prevalence of anxiety or depression and related risk factors in women during pregnancy and postpartum. Chin Ment Health J. 2007;21(4):254-8.

4. Zeng Y, Cui Y, Li J. Prevalence and predictors of antenatal depressive symptoms among Chinese women in their third trimester: a cross-sectional survey. BMC Psychiatry. 2015;15:66

5. Mo Y, Gong W, Wang J, Sheng X, Xu DR. The association between the use of antenatal care smartphone apps in pregnant women and antenatal depression: cross-sectional study. JMIR Mhealth Uhealth. 2018;6(11):e11508.

6. Roomruangwong C, Kanchanatawan B, Sirivichayakul S, Maes M. Antenatal depression and hematocrit levels as predictors of postpartum depression and anxiety symptoms. Psychiatry Res. 2016;238:211-7.

7. Matijasevich A, Murray J, Cooper PJ, Anselmi L, Barros AJD, Barros FC, Santos IS. Trajectories of maternal depression and offspring psychopathology at 6 years: 2004 Pelotas cohort study. J Affect Disord. 2015;174:424-31.

8. Stewart DE. Clinical practice. Depression during pregnancy. N. Engl. J. Med. 2011:365(17):1605-11.

9. Underwood L, Waldie K, D'Souza S, Peterson ER, Morton S. A review of longitudinal studies on antenatal and postnatal depression. Arch Womens Ment Health. 2016;19(5):711-20.

10. Rwakarema M, Premji SS, Nyanza EC, Riziki P, Palacios-Derflingher L. Antenatal depression is associated with pregnancy-related anxiety, partner relations, and wealth in women in northern Tanzania: a cross-sectional study. BMC Womens Health. 2015;15:68.

11. Biaggi A, Conroy S, Pawlby S, Pariante CM. Identifying the women at risk of antenatal anxiety and depression: a systematic review. J Affect Disord. 2016; 191:62-77.

12. Lee $\mathrm{SH}$, Kuo CP, Hsiao CY, Lu YC, Hsu MY, Kuo PC, Lee MS, Lee MC. Development of a Chinese childbearing attitude questionnaire for infertile women receiving in vitro fertilization treatment. J Transcult Nurs. 2013;24(2): 127-33.

13. Lau Y, Yin L, Wang Y. Antenatal depressive symptomatology, family conflict and social support among Chengdu Chinese women. Matern Child Health J. 2011;15(8):1416-26.

14. Benvenuti $P$, Ferrara M, Niccolai $C$, Valoriani V, Cox JL. The Edinburgh postnatal depression scale: validation for an Italian sample. J Affect Disord. 1999:53(2):137-41.

15. Zhao Y, Munro-Kramer ML, Shi S, Wang J, Zhu X. A longitudinal study of perinatal depression among Chinese high-risk pregnant women. Women Birth. 2018;31(6):e395-402. 
16. Wang Y, Guo X, Lau Y, Chan KS, Yin L, Chen J. Psychometric evaluation of the mainland Chinese version of the Edinburgh postnatal depression scale. Int J Nurs Stud. 2009;46(6):813-23.

17. Gavin NI, Gaynes BN, Lohr KN, Meltzer-Brody S, Gartlehner G, Swinson T. Perinatal depression: a systematic review of prevalence and incidence. Obstet Gynecol. 2005;106(5 Pt 1):1071-83.

18. Bennett HA, Einarson A, Taddio A, Koren G, Einarson TR. Prevalence of depression during pregnancy: systematic review. Obstet Gynecol. 2004; 103(6):698-709.

19. Klainin P, Arthur DG. Postpartum depression in Asian cultures: a literature review. Int J Nurs Stud. 2009:46(10):1355-73.

20. Bayrampour H, McDonald S, Tough S. Risk factors of transient and persistent anxiety during pregnancy. Midwifery. 2015;31(6):582-9.

21. Pariante CM. Depression during pregnancy: molecular regulations of mothers' and children's behaviour. Biochem Soc Trans. 2014;42(2):582-6.

22. Getinet W, Amare T, Boru B, Shumet S, Worku W, Azale T. Prevalence and risk factors for antenatal depression in Ethiopia: systematic review. Depress Res Treat. 2018;2018:3649269.

23. Ahmed A, Feng C, Bowen A, Muhajarine N. Latent trajectory groups of perinatal depressive and anxiety symptoms from pregnancy to early postpartum and their antenatal risk factors. Arch Womens Ment Health. 2018:21(6):689-98.

24. Castro e Couto T, Cardoso MN, Brancaglion MY, Faria GC, Garcia FD, Nicolato R, de Miranda DM, Corrêa H. Antenatal depression: Prevalence and risk factor patterns across the gestational period. J Affect Disord. 2016;192:70-5.

25. Gjerdingen D, McGovern P, Attanasio L, Johnson PJ, Kozhimannil KB. Maternal depressive symptoms, employment, and social support. J Am Board Fam Med. 2014;27(1):87-96.

26. Qiao YX, Wang J, Li J, Ablat A. The prevalence and related risk factors of anxiety and depression symptoms among Chinese pregnant women in Shanghai. Aust N Z J Obstet Gynaecol. 2009;49(2):185-90.

27. Schmidt L, Sobotka T, Bentzen JG. Nyboe Andersen a; ESHRE reproduction and society task force. Demographic and medical consequences of the postponement of parenthood. Hum Reprod Update. 2012;18(1):29-43.

28. Busby Grant J, Bruce CP, Batterham PJ. Predictors of personal, perceived and self-stigma towards anxiety and depression. Epidemiol Psychiatr Sci. 2016; 25(3):247-54.

29. Adewuya AO, Fatoye FO, Ola BA, ljaodola OR, Ibigbami SM. Sociodemographic and obstetric risk factors for postpartum depressive symptoms in Nigerian women. J Psychiatr Pract. 2005;1 1(5):353-8.

30. Mora PA, Bennett IM, Elo IT, Mathew L, Coyne JC, Culhane JF. Distinct trajectories of perinatal depressive symptomatology: evidence from growth mixture modeling. Am J Epidemiol. 2009;169(1):24-32.

31. Chung EK, McCollum KF, Elo IT, Lee HJ, Culhane JF. Maternal depressive symptoms and infant health practices among low-income women. Pediatrics. 2004;113(6):e523-9.

32. Ad AF, Vasconcelos AG, Neves FS, Laks J, Correa H. Affective temperaments: familiality and clinical use in mood disorders. J Affect Disord. 2013;148(1):53-6.

\section{Publisher's Note}

Springer Nature remains neutral with regard to jurisdictional claims in published maps and institutional affiliations.

Ready to submit your research? Choose BMC and benefit from:
- fast, convenient online submission
- thorough peer review by experienced researchers in your field
- rapid publication on acceptance
- support for research data, including large and complex data types
- gold Open Access which fosters wider collaboration and increased citations
- maximum visibility for your research: over 100M website views per year
At BMC, research is always in progress.
Learn more biomedcentral.com/submissions

